\title{
The second-order conditioning of fear in rats
}

\author{
ALAN C. KaMIL \\ UNIVERSITY OF MASSACHUSETTS
}

The phenomenon of second-order conditioning (SOC) in rats was investigated, using the conditioned suppression technique. $A$ between groups noncontingent stimulus presentation control procedure was employed. Significant SOC was obtained providing additional evidence for the reality of the SOC phenomenon.

The phenomenon of second-order conditioning (SOC) has recently come under renewed experimental attack (Davenport, 1966; McAllister \& McAllister, 1964; Murphy \& Miller, 1957). The most convincing successful demonstration of SOC has been that of Davenport (1966) employing the conditioned suppression technique. In this experiment Davenport ran both within-andbetween-subject controls. In addition, one-trial-perday scheduling was employed and SOC trials were not intermixed with UCS presentations.

The present research was designed to supplement that of Davenport. The between-subject control technique of noncontingent stimulus presentations, recently suggested by Rescorla (1967) for classical conditioning, was used rather than the backward conditioning controls of Davenport. Unlike the Davenport report, the present experiment utilized a single training procedure throughout, making direct experimental-control comparisons possible.

Methed

The Ss were 24 experimentally naive male albino rats of the Holtzman strain, 140-145 days old at the start of the experiment. The Ss were maintained at $80 \%$ of their free-feeding weight throughout the experiment. Six Ss were discarded curing running, four due to illness and two for failure to generate stable baseline response rates.

The apparatus consisted of four Gerbrands Model $\mathrm{C}$ rat test chambers, controlled by standard programming equipment. $\mathrm{CS}_{1}$ was a $74 \mathrm{~dB}, 450 \mathrm{cps}$ tone of $10 \mathrm{sec}$ duraHion which interrupted the ambient white noise level of $77 \mathrm{~dB} . \mathrm{CS}_{2}$ was the increase in illumination provided by increasing the houselight and cue light voltage from $10 \mathrm{VAC}$ to $20 \mathrm{VAC}$, and was of $30 \mathrm{sec}$ duration. The UCS was an 0.5 sec grid shock delivered to all four chambers, which were wired in parallel, by a GrasonStadler shock generator set at a nominal voltage of $4 \mathrm{~mA}$.

Throughout the experiment each daily session was $23.1 \mathrm{~min}$ long. With one exception no more than one trial per session was ever given. Trial onset was in the middle $13.1 \mathrm{~min}$ of a session, and was randomly determined each day. The experiment was run in five stages, all Ss treated identically through the first four. In Stage $1 \mathrm{Ss}$ received standard bar press training followed by 24 sessions of VI-60 sec LH-20 sec experience (a lapse of 34 days was necessary between Sessions 7 and 8 of this stage; otherwise Ss were run daily). In Stage 2, Pre-exposure $1, \mathrm{CS}_{1}$ was exposed without programmed consequence for four trials. In Stage 3 , first-order conditioning (FOC), $\mathrm{CS}_{1}$ was paired with the UCS in a delay conditioning paradigm for seven trials. Two sessions in which no trial was given were interspersed among the seven FOC sessions. In Stage 4, Pre-exposure 2, $\mathrm{CS}_{2}$ was presented without programmed consequence for six trials. The first two trials of this stage were presented in the same session.

At the end of Pre-exposure 2, the 18 remaining Ss were randomly divided into two groups of nine Ss each. During the 10 trials of the SOC phase members of the experimental group were presented with $\mathrm{CS}_{2}$ followed by $\mathrm{CS}_{1}$ (no UCS was presented) in a delay conditioning paradigm. The control group received noncontingent presentations of $\mathrm{CS}_{1}$ and $\mathrm{CS}_{2}$ for 10 trials. The schedule of these noncontingent presentations was determined as follows: the interval between $\mathrm{CS}_{1}$ onset and $\mathrm{CS}_{2}$ onset was allowed to vary between plus and minus $250 \mathrm{sec}$. The resulting $500 \mathrm{sec}$ range was divided into ten $50 \mathrm{sec}$ segments. Using a table of random numbers one particular time from each interval was selected and assigned to a trial. It was felt that although this procedure was a technical violation of Rescorla's (1967) suggestion of random presentation, it was necessary in order to insure a balanced schedule of stimulus presentations within the relatively few trials available for study during SOC.

The dependent variable used throughout the experiment was response suppression. This was measured by a ratio of the form $R_{C S} /\left(R_{C S}+R_{p}\right)$, in which $R_{C S}$ is the rate of responding during the $C S$ and $R_{p}$ the rate during the $100 \mathrm{sec}$ interval immediately preceding the trial.

\section{Results and Discussion}

The results of the experiment are presented in Fig. 1. It is clear that there were no significant differences between the experimental and control groups in Preexposure 1, FOC, or Pre-exposure 2. A groups by days analysis of variance was performed on the results of each stage. There were no significant effects during Pre-exposure 1. The only significant effect during FOC was a decrease in the suppression ratio across trials $(F=34.45, \mathrm{df}=6 / 96, p<.001)$ representing the fear conditioning process. During Pre-exposure 2 there was a significant increase in the suppression ratio across trials $(F=3.97$, df $=4 / 64, p<.001)$ due to the adaptation of the novelty effects of $\mathrm{CS}_{2}$.

Two analyses were performed on the data obtained 

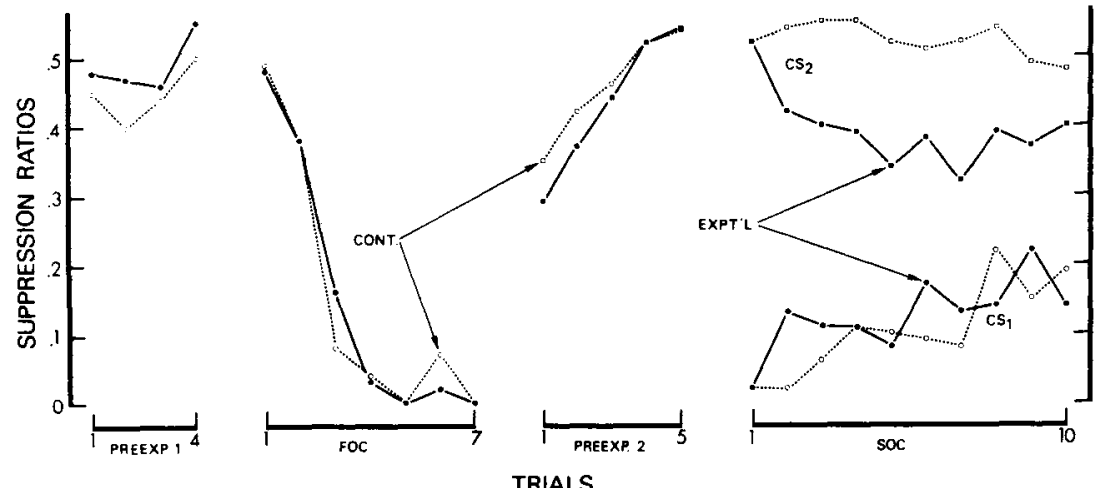

during the SOC phase. In the analysis of $\mathrm{CS}_{1}$ suppression during SOC there was one significant effect, an increase in mean $\mathrm{CS}_{1}$ suppression ratio across $\mathrm{SOC}$ trials $(F=2.99$, $d f=9 / 144, p<.01)$. In performance during $\mathrm{CS}_{2}$, the experimental group displayed significantly more suppression than did the controls $(F=11.24$, $\mathrm{df}=1 / 6, \mathrm{p}<.01$ ). This was the only significant term involving groups in any of the analyses performed.

These findings represent a clear demonstration of second-order conditioning. This conclusion is further supported by the fact that both groups performed similarly during $\mathrm{CS}_{1}$ in the SOC phase since this would seem to further eliminate any pseudoconditioning arguments. It is also interesting to note that the $\mathrm{CS}_{2}$ performance of the controls during SOC was neutral throughout with neither increased nor decreased response rate during this stimulus. This is what one would expect since, as Rescorla (1967) points out, with the noncontingent control procedure $\mathrm{CS}_{2}$ has no signal or information value.

\section{References}

DAVENPORT, J. W. Higher-order conditioning of fear. Psychon. Sci., $1966,4,27-28$.

MCALLISTER, D. E., \& McALLISTER, W. R. Second-order conditioning of fear. Psychon. Sci. 1964, 1, 383-384.

MURPHY, J. V., \& MILLER, R. E. Higher-order conditioning in the monkey. J. gen. Psychol, 1957, 56, 67-72.

RESCORLA, R. A. Pavlovian conditioning and its proper control precedures. Psychol. Rev., 1967, 74, 71-80.

Note

1. This research was carried out while the author was a research assistant at the University of Wisconsin Regional Primate Research Center and was supported by Grant FR-00167 from the National Institutes of Health. The encouragement of John W. Davenport is gratefully acknowledged. 